\title{
COMPREHENSIVE ASSESSMENT OF THE EFFECTIVENESS OF THE DEVELOPMENT OF JOINT-STOCK COMPANIES IN THE BUILDING MATERIALS INDUSTRY
}

\author{
Dekhkanov Sherzod Abdumutalibovich \\ Fergana Polytechnic Institute
}

\begin{abstract}
ANNOTATION
The article discusses systems for the comprehensive assessment of the effectiveness of corporations, which allow linking various financial, production, personnel and other characteristics of corporations' activities in a single coordinate system.

KEY WORDS: Corporation, finance, production, personnel issues, descriptions of corporations, coordinates.
\end{abstract}

\section{Комплексная оценка эффективности развития акционерных обществ в отрасли строительных материалов}

\author{
Дехканов Шерзод Абдумуталибович, \\ Ферганский политехнический институт, \\ соискатель,
}

Аннотация. В статье рассматриваются системы комплексной оценки эффективности корпораций, позволяюшче связать различные финансовые, производственные, кадровые и другие характеристики деятельности корпораций в единой системе координат.

Ключевые слова: Корпорация, финансы, производство, кадровые вопросы, описания корпораций, координатьл.

Сегодня при развитии акционерных обществ важна комплексная количественная оценка эффективности корпоративного управления.

Следует отметить, что в настоящее время не существует единого общепринятого подхода к комплексной оценке эффективности развития корпораций, позволяющего связать различные финансовые, производственные, кадровые и другие характеристики корпораций в единой системе координат. Одним из наиболее всеобъемлющих инструментов изучения эффективности корпоративного 


\section{EPRA International Journal of Research and Development (IJRD)}

Volume: 6 | Issue: 7 | July 2021

- Peer Reviewed Journal

развития является метод создания сбалансированной индикаторной системы (BSC), который был основан в 1990 году американскими экономистами Р. Капланом и Д. Нортоном ${ }^{1}$

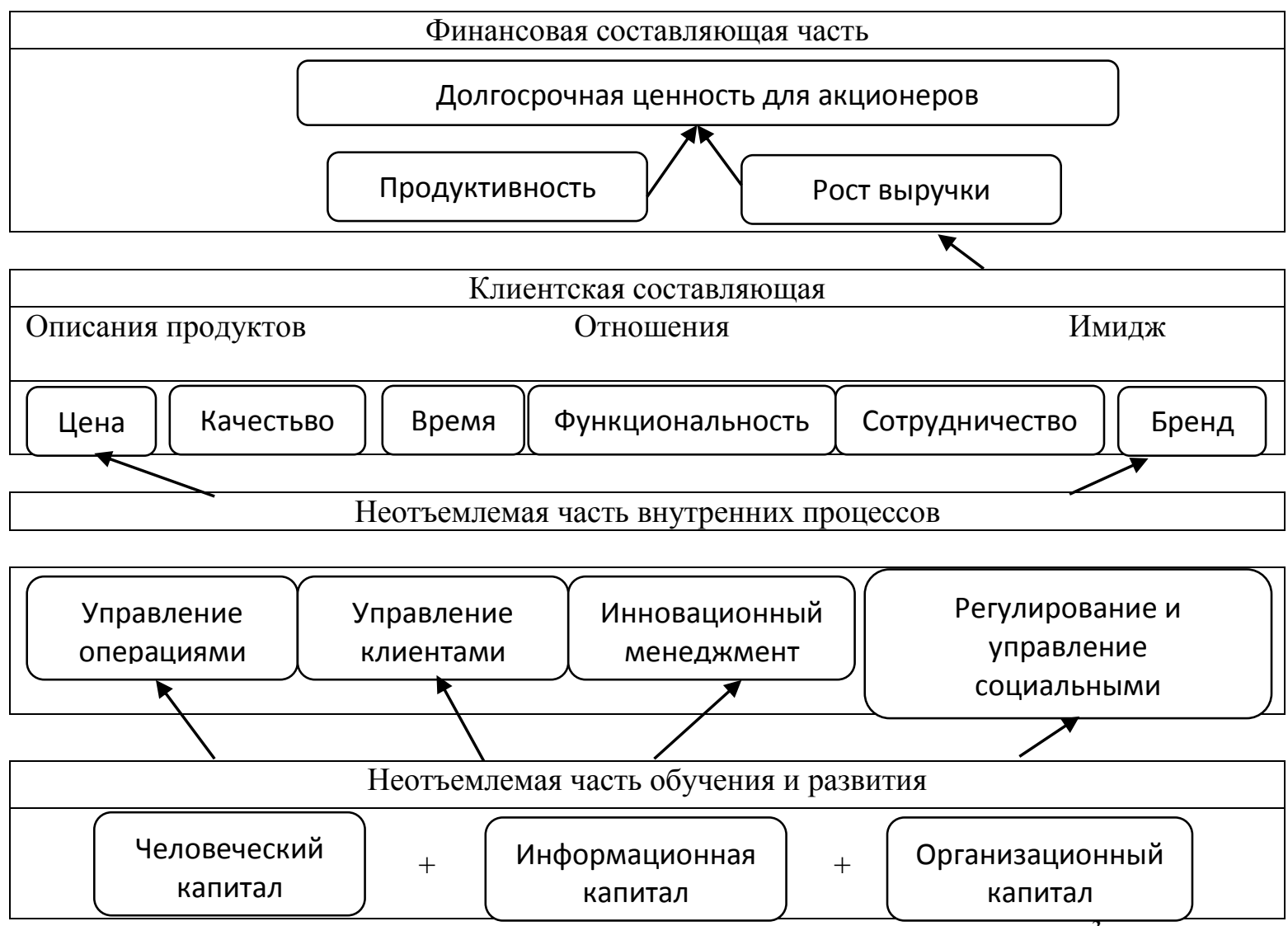

Рисунок 1. Общий вид ВSC по методике Р. Каплана и Д. Нортона 2

Согласно классической методологии сбалансированной системы показателей, все показатели развития компании делятся на четыре основных блока: финансовый блок (финансовая составляющая BSC), клиентский блок; блок внутреннего процесса; блок обучения и развития. Внутри каждого блока Р. Каплан и Д. Нортон, по их мнению, выделяют ряд показателей, которые четко и всесторонне описывают эффективность развития компании. Методология сбалансированной системы показателей - более популярный инструмент для оценки результатов деятельности компаний с разными формами собственности и видами экономической деятельности.

В классической версии BSC отсутствует блок показателей, характеризующих качество корпоративного управления. Методические рекомендации по комплексной оценке эффективности управления акционерными обществами разработаны путем разработки методологического инструментария для сбалансированной системы показателей.

Предлагается выделить четыре блока показателей, которые представляют разные важные области корпоративной деятельности: корпоративное управление, деятельность человеческого капитала, производственно-инвестиционные и финансовые процессы. В частности, производственноинвестиционный блок в самом общем виде - это производственная деятельность корпорации и ее инвестиционное развитие; финансовый блок - финансовая поддержка различных процессов в развитии корпорации; блок качества корпоративного управления - особенности управления корпоративной собственностью; блок человеческого капитала - описывает будущее кадровое обеспечение развития корпорации и ее эффективность. Выделенные блоки показателей эффективности корпоративного развития представлены на рисунке 2 , основные направления взаимодействия.

\footnotetext{
${ }^{1}$ Каплан Р., Нортон Д. Сбалансированная система показателей. От стратегии к действиям. - М.: Олимпбизнес, 2013; Каплан Р., Нортон Д. Стратегические карты. - М.: Олимп-бизнес, 2012. - 486 с.

${ }^{2}$ Каплан Р., Нортон Д. Стратегические карты. - М.: Олимп-бизнес, 2012. С. 79.
} 
Блок человеческого капитала корпорации

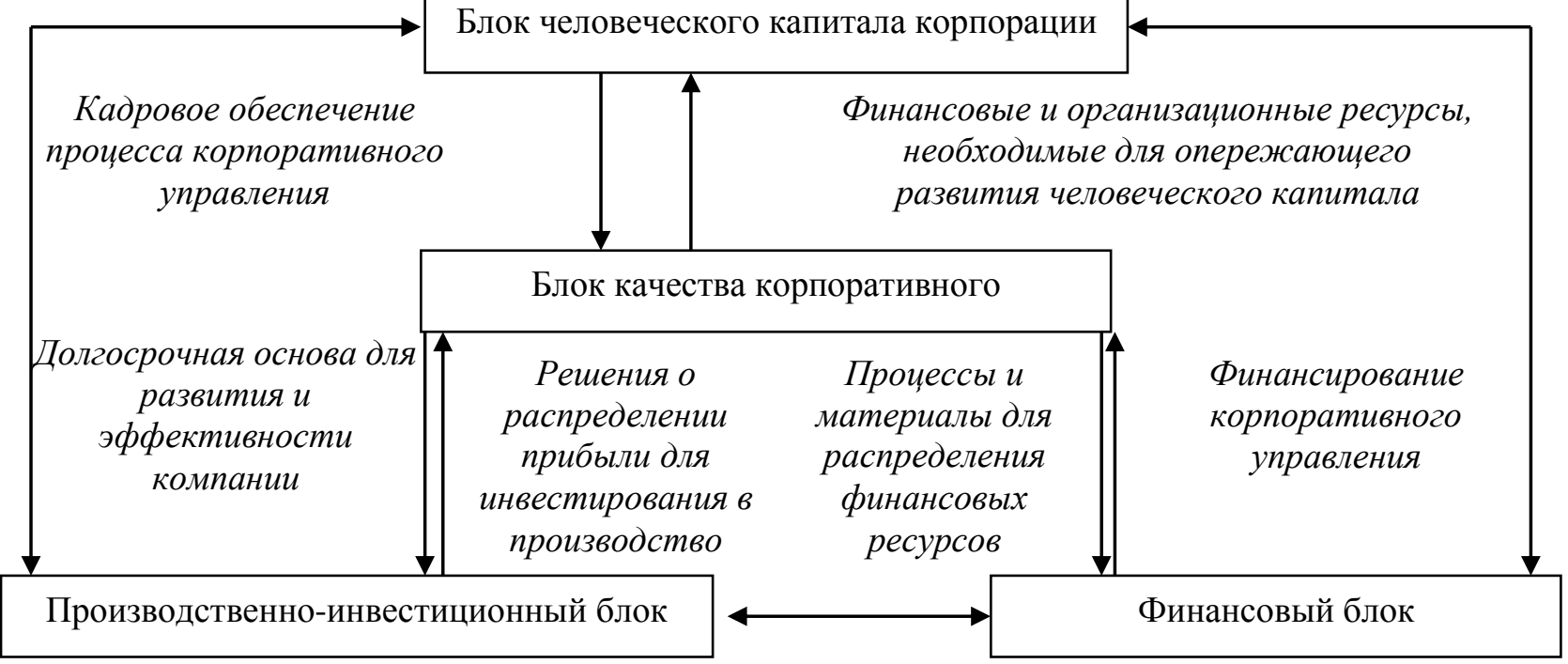

\section{Рисунок 2. Комплексная оценка эффективности управления в акционерных обществах ${ }^{3}$}

В каждом блоке идентифицируются некоторые из наиболее важных показателей, стандарт скорости их изменения, определяется наиболее предпочтительная последовательность, затем распределение темпов роста показателей развития конкретной корпорации на практике сравнивается с эталонным показателем.

Стандартными являются следующие законы скорости изменения показателей в рамках блока качества корпоративного управления:

$$
\mathrm{KA}>1 \text { / TC> } 1 \text { / N }>\mathrm{UR}>1 \text { / VSD (1) }
$$

здесь:

КА - скорость изменения цены акций корпорации по отношению к динамике фондового индекса за тот же период;

ТC - скорость изменения объема транзакционных издержек, связанных с организацией и внедрением процессов корпоративного управления (корпоративное обеспечение споров с акционерами корпорации, стоимость организации и проведения общих собраний акционеров);

$\mathrm{N}$ - скорость изменения количества нарушений, выявленных регулирующими органами по вопросам корпоративного управления;

UR - скорость изменения доли предложений Совета директоров, принятых на следующем годовом общем собрании акционеров;

VSD - это скорость изменения общей суммы вознаграждения членов Совета директоров корпорации.

Показатели качества корпоративного управления можно описать следующим образом:

1. Фондовый рынок является основным, достаточно объективным показателем качества корпоративного управления при условии, что его акции достаточно прозрачны и конкурентоспособны для корпораций, акции которых имеют регулярную рыночную котировку. Действительно, нельзя делать никаких передовых инноваций в организации и реализации процесса корпоративного управления, включая взаимоотношения между государством как акционером и результатами производственной деятельности корпорации и других групп собственников средств, но при устойчивом снижении в ценах акций такое корпоративное управление можно считать эффективным, если оно может быть достигнуто. Поэтому динамика курса акций принята как наиболее общий критерий качества корпоративного управления в рамках предложенной методологии.

2. Скорость снижения транзакционных издержек, связанных с организацией и внедрением процессов корпоративного управления, предлагается рассматривать как вторичный критерий эффективности с точки зрения приоритезации блока качественных показателей корпоративного управления. К таким расходам относятся, в первую очередь, убытки из-за споров с различными

\footnotetext{
${ }^{3}$ Каплан Р., Нортон Д. Стратегические карты. - М.: Олимп-бизнес, 2012. С. 79.
} 


\section{EPRA International Journal of Research and Development (IJRD) \\ Volume: 6 | Issue: 7 | July 2021 \\ - Peer Reviewed Journal}

группами акционеров корпорации. Соответственно, эти виды затрат ограничивают возможности корпораций по повышению своей коммерческой эффективности, увеличению суммы дивидендных выплат акционерам и реинвестированию в развитие корпорации. Таким образом, предлагается рассматривать целевое снижение таких транзакционных издержек как один из важнейших критериев качества корпоративного управления.

3. В рамках данного блока показателей предлагается рассмотреть снижение количества нарушений при организации и реализации корпоративного управления, определенное надзорными органами в качестве следующего приоритета. Снижение количества таких нарушений - важный критерий повышения качества корпоративного управления в акционерном обществе.

4. Важна также доля предложений Совета директоров, принятых общим собранием акционеров в соответствии с предложенной последовательностью качественных показателей корпоративного управления. Этот показатель отражает уровень согласованности развития различных органов управления акционерного общества.

5. Также важен размер вознаграждения, выплачиваемого членам Совета директоров Корпорации. Изменение размера такого вознаграждения повлияет на эффективность руководящего органа корпорации, который так же важен, как и Совет директоров, поскольку предыдущие показатели эффективности корпорации улучшаются.

Таким образом, выделенные индикаторы описывают различные аспекты оценки качества корпоративного управления: фондовым рынком и регулирующими органами, с точки зрения координации различных групп, так или иначе вовлеченных в процесс корпоративного управления.

Согласно предложенной методике, эталонные последовательности скорости изменения показателей в блоке человеческого капитала корпорации будут иметь следующий вид:

$$
\mathrm{IHK}>\mathrm{LP}>\mathrm{SL}>\mathrm{P}>\mathrm{W}(2)
$$

здесь:

IHK - скорость изменения общих вложений в развитие человеческого капитала корпорации (все косвенные затраты на развитие персонала - дополнительное медицинское страхование, дополнительные пенсии для наиболее ценных членов корпорации, обучение персонала за счет корпорации, размер выплат руководителям дополнительных программ), т.е.все расходы на персонал за вычетом фонда заработной платы);

LP - скорость изменения уровня производительности труда в корпорации;

SL - скорость изменения средней заработной платы сотрудников компании;

P - скорость изменения средней штатной численности корпоративного персонала;

$\mathrm{W}$ - скорость изменения количества сотрудников.

На наш взгляд, темпы роста корпоративных инвестиций в человеческий капитал, включающие в себя все косвенные затраты на развитие персонала акционерного общества, должны быть максимальными. Инвестиции в человеческий капитал - один из важнейших стратегических факторов повышения эффективности компании.

В то же время следует отметить, что большое количество современных местных организаций, в том числе являющихся по организационно-правовой форме акционерными обществами, стараются существенно сэкономить на инвестициях в развитие и совершенствование человеческого капитала.

На наш взгляд, тот факт, что корпорации не полностью финансируют затраты на воспроизводство человеческого капитала, является одним из важных факторов недостаточной производительности труда и, как следствие, финансово-экономической эффективности их деятельности. Поэтому темпы роста стоимости развития человеческого капитала корпорации выделены как приоритетные в данной группе показателей для оценки эффективности развития корпорации.

В целом предлагаемая методика комплексной оценки эффективности корпоративного управления и приоритетов влияния государства на ее совершенствование представляет собой количественную оценку эффективности корпоративного развития в блоке качества корпоративного управления, блоке человеческого капитала, производственно-инвестиционном блоке. финансовый блок, выявление и мобилизация таких ресурсов для оправдания мер государственного влияния через корпоративные и другие связанные механизмы.

\section{Список использованной литературы}

1. Хамидулин М. Корпоративное управление: подробнее по конкретным вопросам / Управление предприятием №5 (35), 2010. с.6.

2. Ходиев Б.Ю. и другие. Корпоративное управление. Методическое пособие. - Т .: ТДИУ, 2010. - 210 c. 
3. Ханкельдиева Г.Ш. Особенности корпоративного управления в акционерных обществах с государственным участием // Вестник науки и практики. Электрон. юрн. 2017. №11 (24). С. 357-363. Pежим доступа: http://www.bulletennauki.com/honkeldiyeva

4. Хонкельдиева К., Маматкулова Ф. (2020). Социально-экономические аспекты устойчивого развития предприятия. В Науке сегодня: факты, тенденции, прогнозы (с. 36-37).

5. Ханкельдиева Г.Ш. Теоретические и экономические предпосылки развития региональных промышленных кластеров в экономике республики узбекистан // EPRA International Journal of Research and Development (IJRD). - 2020. - C. 234-240. https://doi.org/10.36713/ epra 4855.

6. Ксанкельдиева Г. Ш. Перспективы развития электроэнергетической отрасли Республики Узбекистан в условиях модернизации экономических отнотений // Вестник науки и практики. Электрон. июн. 2017. №12 (25). C. 293-299. Доступный режим: http://www.bulletennauki.com/honkeldiyeva-g (обращения данные 15.12.2017). 